\title{
Endocytotic uptake of HPMA-based polymers by different cancer cells: impact of extracellular acidosis and hypoxia
}

This article was published in the following Dove Press journal:

International Journal of Nanomedicine

3 August 2017

Number of times this article has been viewed

\author{
Daniel Gündel' \\ Mareli Allmeroth ${ }^{2}$ \\ Sarah Reimel \\ Rudolf Zentel ${ }^{2}$ \\ Oliver Thews' \\ 'Institute of Physiology, Martin \\ Luther University Halle-Wittenberg, \\ Halle (Saale), ${ }^{2}$ Institute of Organic \\ Chemistry, Johannes Gutenberg- \\ University, Mainz, Germany
}

Background: Polymeric nanoparticles allow to selectively transport chemotherapeutic drugs to the tumor tissue. These nanocarriers have to be taken up into the cells to release the drug. In addition, tumors often show pathological metabolic characteristics (hypoxia and acidosis) which might affect the polymer endocytosis.

Materials and methods: Six different $N$-(2-hydroxypropyl)methacrylamide (HPMA)-based polymer structures (homopolymer as well as random and block copolymers with lauryl methacrylate containing hydrophobic side chains) varying in molecular weight and size were analyzed in two different tumor models. The cellular uptake of fluorescence-labeled polymers was measured under hypoxic $\left(\mathrm{pO}_{2} \approx 1.5 \mathrm{mmHg}\right.$ ) and acidic ( $\mathrm{pH}$ 6.6) conditions. By using specific inhibitors, different endocytotic routes (macropinocytosis and clathrin-mediated, dynamin-dependent, cholesterol-dependent endocytosis) were analyzed separately.

Results: The current results revealed that the polymer uptake depends on the molecular structure, molecular weight and tumor line used. In AT1 cells, the uptake of random copolymer was five times stronger than the homopolymer, whereas in Walker-256 cells, the uptake of all polymers was much stronger, but this was independent of the molecular structure and size. Acidosis increased the uptake of random copolymer in AT1 cells but reduced the intracellular accumulation of homopolymer and block copolymer. Hypoxia reduced the uptake of all polymers in Walker-256 cells. Hydrophilic polymers (homopolymer and block copolymer) were taken up by all endocytotic routes studied, whereas the more lipophilic random copolymer seemed to be taken up preferentially by cholesterol- and dynamin-dependent endocytosis.

Conclusion: The study indicates that numerous parameters of the polymer (structure, size) and of the tumor (perfusion, vascular permeability, $\mathrm{pH}, \mathrm{pO}_{2}$ ) modulate drug delivery, which makes it difficult to select the appropriate polymer for the individual patient.

Keywords: HPMA-LMA copolymers, endocytosis, tumor microenvironment, tumor lines, structure-property relationship

\section{Introduction}

Nanoscale drug carriers are a promising approach to transport chemotherapeutic agents specifically to the tumor tissue and to protect normal tissues from toxic side effects. In this study, the enhanced vascular permeability of the tumor vasculature is utilized, which allows large molecular structures $(>40 \mathrm{kDa})$ to leave the bloodstream and to accumulate in the tumor tissue. ${ }^{1}$ Various chemical structures have been suggested to serve as carriers: liposomes, nanocapsules or polymers. ${ }^{2}$ However, in liposomes 
or nanocapsules, the chemotherapeutics are dissolved in the liquid core of the structure; in polymer-drug-conjugated nanoparticles, the drug is directly bound to the polymer backbone. Liposomes or nanocapsules can deliver the drug to the cells by extracellular decomposition of the enveloping structure, by fusion with the cell membrane or by endocytosis. With polymeric nanoparticles, the drug is mostly cleaved enzymatically. Therefore, polymer carriers have to be taken up into the cells by endocytosis. ${ }^{2}$ Besides phagocytosis, several endocytotic routes have been described for the uptake of free (water soluble) molecules or membrane receptor-bound compounds..$^{2-4}$ Macropinocytosis is a process for direct drug uptake from the fluid phase during which actin-driven membrane protrusions form a vesicle, which is then incorporated into the cell (macropinosome). During clathrin-mediated endocytosis (CME), intracellular clathrin molecules form a network around a membrane invagination. Afterward, the membrane scission protein dynamin (a guanosine triphosphate hydrolase [GTPase]) unhitches the clathrin-coated pit from the cell membrane. A clathrin-independent mechanism is the caveolae-mediated endocytosis, which is cholesteroldependent requiring cholesterol-rich microdomains (rafts) in the cell membrane associated with caveolin-1 to form caveolar vesicles. In this process, the detachment of the vesicle from the cell membrane probably also requires dynamin. ${ }^{2,3,5}$ But cholesterol is also essential for CME. ${ }^{6}$

Suitable chemical structures for the design of polymer nanoparticles should be nontoxic, nonimmunogenic and degradable. One promising compound fulfilling these requirements is poly- $N$-(2-hydroxypropyl)methacrylamide (p[HPMA]) polymers that have been already tested in preclinical as well as clinical studies. ${ }^{7-9}$ Further development of these hydrophilic $N$-(2-hydroxypropyl)methacrylamide (HPMA) homopolymers led to the design of copolymers containing lipophilic lauryl methacrylate (LMA) segments within the HPMA backbone. These HPMA-LMA copolymers (p(HPMA)-co-p(LMA) and p(HPMA)- $b$-p(LMA) copolymers) have been shown to improve the drug transport through the blood-brain barrier. ${ }^{10,11}$ The lipophilic segments orientate themselves in the core, whereas the hydrophilic HPMA segments are located in the shell. Depending on the chemical structure of these molecules and on the ratio of lipophilic LMA segments in the HPMA backbone, the HPMA-LMA copolymers form self-assembled structures in which several polymer chains are aggregated (micellar superstructures). In random $\mathrm{p}$ (HPMA)-co-p(LMA) copolymers, most of the LMA elements are oriented in the core; however, numerous lipophilic segments are also located on the surface of the polymer nanoparticle. ${ }^{10-13}$ The $\mathrm{p}$ (HPMA)$b$-p(LMA) block copolymers, which are synthesized from HPMA and HPMA-LMA oligomers (blocks), show a strict lipophilic core and a hydrophilic surface. ${ }^{11,12,14,15}$ It was found that homopolymers and random and block copolymers show profoundly different biological behavior in vivo. ${ }^{13-16}$ On the macroscopic scale, homopolymer and block copolymers accumulated preferentially in the spleen and liver, whereas the random copolymer stayed more pronounced in the blood. When analyzing the overall accumulation in solid-growing AT1 prostate and Walker-256 mammary carcinomas, the intratumoral concentration of the random copolymer was more than twice the level of the homopolymer or the block copolymer. However, in these studies, ${ }^{14,15}$ only the whole tissue concentration was measured, and it could not be differentiated whether the polymers entered the cells or stayed in the extracellular space. For this reason, the cellular uptake in these two cell lines was analyzed in the current study.

Finally, it is well known that the metabolic microenvironment of tumors is profoundly different from that in normal tissues. Many tumors show hypoxic/anoxic regions, and the glycolytic metabolism is intensified leading to a marked extracellular acidosis with $\mathrm{pH}$ values down to $6 .{ }^{17,18}$ It has been shown that hypoxia can decelerate different routes of endocytosis (CME and clathrin-independent endocytosis) mostly via the key regulator hypoxia-inducible factor (HIF). ${ }^{19-21}$ An acidic extracellular environment has also been described to modulate endocytosis/phagocytosis in macrophages. ${ }^{22-24}$ On the other hand, studies revealed that the chemical structure of polymers may also play a role for their endocytotic uptake. Liu et $\mathrm{al}^{25}$ demonstrated that HPMA-based polymers containing alkaline side chains, eg, 2-(N,N-dimethylamino) ethyl methacrylate (positive $\zeta$ potential), were taken up by cells much stronger than polymers containing acidic adducts, eg, methacrylic acid (negative $\zeta$ potential). This mechanism could be of importance in particular in an acidic extracellular environment. But it remains unclear whether the extracellular $\mathrm{pH}$ is also important for the uptake of polymers containing lipophilic segments such as in the HPMA-LMA copolymers studied.

Hypoxia (as a common phenomenon in solid tumors) can limit the ATP yield in the tumor cell, which is the essential energy source for active uptake processes. On the other hand, extracellular acidosis could affect the interaction of the polymer with the cell membrane (eg, by changing the surface charge of the molecule). For these reasons, the aim of the current study was to analyze the impact of hypoxia and extracellular acidosis (which are common characteristics 
of solid-growing tumors) on the uptake of HPMA-based polymer nanoparticles in tumor cells. Therefore, fluorescent HPMA homopolymers as well as random p(HPMA)-co$\mathrm{p}$ (LMA) and p(HPMA)- $b$-p(LMA) block copolymers with low and high molecular weight were synthetized, and the polymer uptake was measured in two different cancer cell lines (AT1 and Walker-256 cells), which have already been studied as solid tumors in vivo. ${ }^{15,16}$ With these models, it was studied whether extracellular acidosis with $\mathrm{pH} 6.6$ or hypoxic conditions $\left(\mathrm{pO}_{2} \approx 1.5 \mathrm{mmHg}\right.$ ) affects the uptake of the different HPMA-based polymers. Finally, to analyze the different endocytotic routes of polymer uptake, inhibitors of specific mechanisms were used to distinguish between macropinocytosis and clathrin-mediated, dynamin-dependent and cholesterol-dependent endocytosis.

\section{Materials and methods Materials}

All chemicals were of analytical grade and obtained from SigmaAldrich Co. (St Louis, MO, USA) and Acros Organics (Thermo Fisher Scientific, Waltham, MA, USA).

\section{Polymer synthesis}

The synthesis of HPMA homopolymers as well as $\mathrm{p}$ (HPMA)-co-p(LMA) and p(HPMA)- $b$-p(LMA) copolymers (Scheme 1) has been described previously together with the characteristics of the polymers, which is summarized in Table $1 .{ }^{14,15}$ Hydrodynamic radii were determined by fluorescence correlation spectroscopy using a commercial setup (Carl Zeiss Microscopy GmbH, Oberkochen, Germany). To ensure the comparability with the biological situation (cell culture and in vivo), polymers were dissolved in isotonic saline for FCS measurements.

The polymers were labeled with Oregon Green-480 (excitation $485 \mathrm{~nm}$, emission $532 \mathrm{~nm}$ ). This fluorochrome has the advantage that its fluorescent is not $\mathrm{pH}$ dependent, which is essential for experiments, in which the extracellular pH was varied.
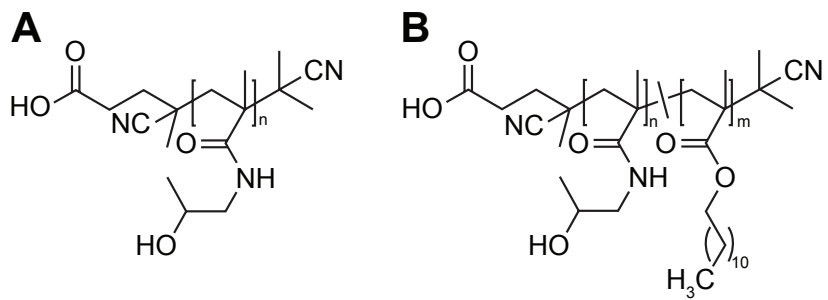

Scheme I Chemical structure of $(\mathbf{A})$ the $\mathrm{P}(\mathrm{HPMA})$ homopolymers and $(\mathbf{B})$ the P(HPMA)-co-p(LMA) copolymers used.

Abbreviations: HPMA, N-(2-hydroxypropyl)methacrylamide; LMA, lauryl methacrylate.

\section{Tumor models}

All studies were performed with two tumor cell lines of the rat: 1) Walker-256 mammary carcinoma (\#CCL-38, American Type Culture Collection [ATCC], Manassas, VA, USA) and 2) subline AT1 of the Dunning prostate carcinoma R3327 (\#500121, CLS Cell Lines Service GmbH, Eppelheim, Germany). Both cell lines were grown in culture in RPMI medium supplemented with $10 \%$ fetal calf serum (FCS) and with $10 \mathrm{mM}$ L-glutamine for Walker-256 cells at $37^{\circ} \mathrm{C}$ under a humidified $5 \% \mathrm{CO}_{2}$ atmosphere and sub-cultivated twice per week.

\section{Cellular uptake of polymers}

For the cellular uptake studies, $10^{6}$ cells were transferred to buffered Ringer's solution. Polymers were dissolved in dimethyl sulfoxide (DMSO), then diluted in Ringer's solution and added to the cell suspension leading to a final polymer concentration of $20 \mu \mathrm{g} / \mathrm{mL}$. Cells were incubated with the polymer for $2 \mathrm{~h}$ at either $4^{\circ} \mathrm{C}$ or $37^{\circ} \mathrm{C}$ (experiments with different time points for the analysis of the time course of polymer uptake are shown in Figures S1 and S2). After this period, cells were washed with PBS and lysated with $0.1 \%$ Triton $\mathrm{X}-100$ solution containing $20 \mathrm{mM} 3-(\mathrm{N}-$ morpholino)propanesulfonic acid (MOPS) buffer ( $\mathrm{pH} 7.4$ ). Oregon Green-480 fluorescence was determined in a plate reader (Infinite M200, Tecan, Männedorf, Switzerland). Measurements at $4{ }^{\circ} \mathrm{C}$ were used to assess the amount of polymer which has been bound to the plasma membrane but not internalized. ${ }^{26}$ The actively accumulated amount of the polymer was calculated from the difference of the measurements at $37^{\circ} \mathrm{C}$ and $4^{\circ} \mathrm{C}$ using a calibration curve of the respective polymer. In addition, the protein content of each sample was assessed (bicinchoninic acid assay [BCA] method) to calculate the number of cells in each well which allowed to estimate the active polymer uptake per cell.

\section{Impact of environmental parameters on polymer uptake}

To assess the impact of the extracellular $\mathrm{pH}$ on the polymer uptake under normoxic conditions (with room air), the Ringer's solution for polymer incubation was either 4-(2hydroxyethyl)-1-piperazineethanesulfonic acid (HEPES) buffered ( $\mathrm{pH}$ 7.4) or 2-(N-morpholino)ethanesulfonic acid (MES) buffered ( $\mathrm{pH}$ 6.6). For experiments under hypoxic conditions, Ringer's solutions and the cell-containing 24-well plates were placed in a hypoxia chamber (InvivO 2400 ; Baker Ruskinn, Sanford, ME, USA) at a $\mathrm{O}_{2}$ fraction of $0.2 \%$ $\left(\mathrm{pO}_{2} \approx 1.5 \mathrm{mmHg}\right.$ ) for the time of polymer incubation. 
Table I Analytical data of HPMA homopolymers as well as of random p(HPMA)-co-p(LMA) copolymer and p(HPMA)-co-p(LMA) block copolymers with low and high molecular weight, respectively ${ }^{14,15}$

\begin{tabular}{llllll}
\hline Polymeric structure & Monomer ratio (\%) & $\mathbf{M}_{\mathbf{n}}(\mathbf{g} / \mathbf{m o l})$ & $\mathbf{M}_{\mathbf{w}}(\mathbf{g} / \mathbf{m o l})$ & $\mathbf{D}^{\mathbf{a}}$ & $\mathbf{R}_{\mathbf{h}}(\mathbf{n m})^{\mathbf{b}}$ \\
\hline Homopolymer & $100^{c}$ & $9,000^{d}$ & $12,000^{d}$ & 1.29 & 1.1 \\
Homopolymer & $100^{c}$ & $52,000^{d}$ & $77,000^{d}$ & 1.49 & 3.0 \\
Random copolymer & $82: 18^{c}$ & $11,000^{d}$ & $14,000^{d}$ & 1.26 & 33.4 \\
Random copolymer & $75: 25^{c}$ & $39,000^{d}$ & $55,000^{d}$ & 1.41 & 39.9 \\
Block copolymer & $79: 21^{c}$ & $9,000^{d}$ & $12,000^{d}$ & 1.24 & 58.7 \\
Block copolymer & $75: 25^{c}$ & $17,000^{d}$ & $21,000^{d}$ & 1.24 & 112.8 \\
\hline
\end{tabular}

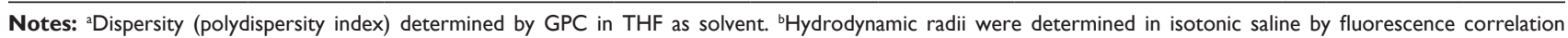
spectroscopy. 'Monomer ratio determined by 'H NMR spectroscopy after a polymer analogous reaction with 2-hydroxypropylamine. ${ }^{\mathrm{d}} \mathrm{Calculated}$ from the molecular weights of the reactive ester polymer precursors as determined by GPC in THF as solvent.

Abbreviations: GPC, gel permeation chromatography; HPMA, N-(2-hydroxypropyl)methacrylamide; LMA, lauryl methacrylate; NMR, nuclear magnetic resonance; THF, tetrahydrofuran.

\section{Different routes of endocytosis for polymer uptake}

To separate different endocytotic routes, cells were incubated (additional to the polymer) with inhibitors of specific mechanisms. Macropinocytosis was blocked by rottlerin, an inhibitor of the protein kinase $\mathrm{C}(\mathrm{PKC}) \delta(10 \mu \mathrm{M})$, dynamin-dependent processes were inhibited by dynasore $(100 \mu \mathrm{M})$ and clathrindependent endocytosis was blocked by chlorpromazine $(50 \mu \mathrm{M})$. Cholesterol-dependent endocytosis was inhibited by cholesterol depletion with nystatin $(30 \mu \mathrm{M}){ }^{3,27,28}$

To study the $\mathrm{pH}$ and $\mathrm{pO}_{2}$ dependencies of these different endocytotic routes, typical substrates of the respective transport mechanisms have been used. Macropinocytosis was measured by the uptake of $70 \mathrm{kDa}$ dextran $(1 \mathrm{mg} / \mathrm{mL})$, CME was assessed by the substrate transferrin $(25 \mu \mathrm{g} / \mathrm{mL})$ and cholesterol-dependent endocytosis by cholera toxin $\beta$ $(2 \mu \mathrm{g} / \mathrm{mL}) .{ }^{29,30}$ These markers were labeled with the fluorophore Oregon Green-488. For these experiments, cells were incubated with the markers for $3 \mathrm{~h}$, and the cellular uptake was assessed by flow cytometry (LSR Fortessa; BD Biosciences, San Jose, CA, USA).

A

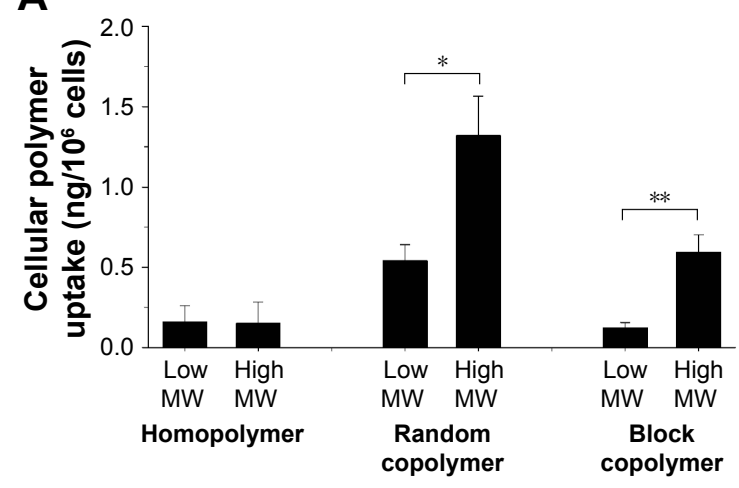

\section{Statistical analysis}

Results are expressed as mean \pm standard error of the mean (SEM). Differences between groups were assessed by the two-tailed Wilcoxon test for paired samples and by multifactorial ANOVA. The significance level was set at $\alpha=5 \%$ for all comparisons.

\section{Results and discussion Uptake of HPMA-based polymers by tumor cells}

Previous studies analyzing the body distribution of the HPMA-based polymers in vivo using ${ }^{18} \mathrm{~F}$-labeled molecules and positron emission tomography (PET) imaging revealed pronounced differences of tumor accumulation depending on the molecular structure and size as well as on the tumor entity. ${ }^{14,15}$ Comparing the two cell lines, the cellular uptake on the microscopic scale showed even stronger differences (Figure 1). In AT1 cells, the uptake was more than 10 times lower than that in Walker-256 cells, whereas in vivo the overall tumor tissue accumulation was more or less comparable in both tumor models. In AT1 cells, pronounced

B

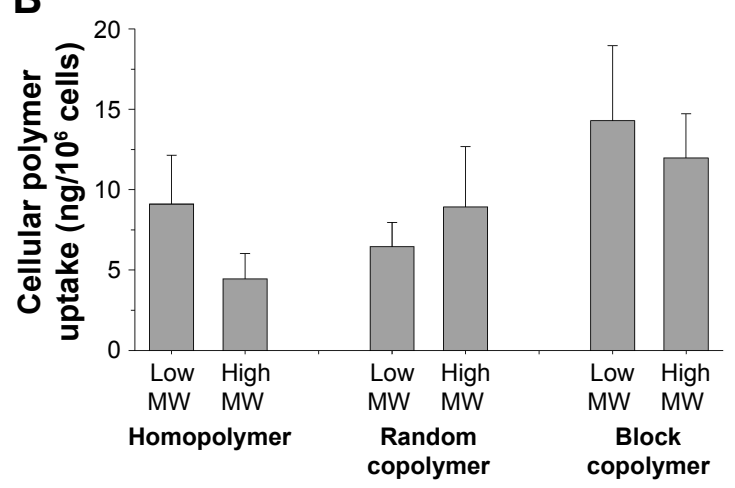

Figure I Cellular uptake of the polymers (homopolymer and random and block copolymers with low and high MW, respectively) in (A) ATI prostate carcinoma cells and (B) Walker-256 mammary carcinoma cells after $2 \mathrm{~h}$.

Notes: $\mathrm{n}=6-9, * \mathrm{p}<0.05, * * \mathrm{p}<0.01$.

Abbreviation: MW, molecular weight. 
differences between the different polymer structures were seen with the random copolymer, where the uptake of random copolymer was much stronger than homopolymer or block copolymer (Figure 1A). In addition, for both copolymers, the uptake of large molecules was significantly stronger than the low-molecular-weight counterpart. For Walker-256 cells, the cellular polymer uptake was almost independent of the molecular structure and the polymer size (Figure 1B). These results indicate no direct correlation between molecular weight and hydrodynamic radius with cellular uptake even though an impact of the particle size cannot be excluded. In vivo, the accumulation in Walker-256 tumors showed marked differences between the various polymers, whereas the accumulation in AT1 tumors was more or less independent of the molecular structure and size..$^{14,15}$ The question arises whether the incubation interval of $2 \mathrm{~h}$ is suitable to study endocytosis since it is known that endocytotic processes can occur more rapidly. However, the advantage of using polymer drug carriers is the long biological half-life resulting in a constantly high blood level and long-lasting tumor uptake. The time course of polymer accumulation showed that the cellular uptake had reached a steady-state level not earlier than after $2 \mathrm{~h}$ (Figures S1 and S2). For this reason, the interval of $2 \mathrm{~h}$ reflected the steady-state conditions of the in vivo situation.

To study the impact of an acidic extracellular environment, cells were exposed acutely to a $\mathrm{pH}$ of 6.6. Compared to control conditions ( $\mathrm{pH}$ 7.4), the polymer uptake was markedly altered (Figure 2). The uptake of homopolymer and block copolymer was reduced by $\sim 50 \%$ in both cell lines. This effect was independent of the molecular size of the polymer. However, due to the variability in homopolymer uptake in the control group, the acidosis-induced reduction was not statistically significant. In contrast, the uptake of random copolymer was significantly stronger in AT 1 cells by a factor of 3-4. In Walker-256 cells in which the uptake under control conditions was much higher as compared to AT1 cells, the acidic condition had almost no impact and was independent of the molecular weight of the polymer (Figure 2). It has to be discussed whether the acidosis-induced changes of polymer uptake might be the result of alterations in surface charge of the polymer. Due to the molecular structure, the HPMA polymers used are slightly negatively charged. It has been shown that the $\zeta$ potential of polymers plays a role for their cellular uptake. ${ }^{25}$ In an acidic environment, the negative surface charge will be reduced, which then may alter endocytosis. However, Figure 2 shows that the uptake increased in random copolymer, whereas it reduced in homopolymer and block copolymer, which also had slightly negatively surface charge. These results may indicate that the uptake changes found (Figure 2) are not solely the result of a change in the $\zeta$ potential.

In contrast, exposing AT1 cells to hypoxia had only minor effect on the polymer uptake (Figure 3). Even though the uptake increased in large random copolymers as well as in small block copolymers, the individual

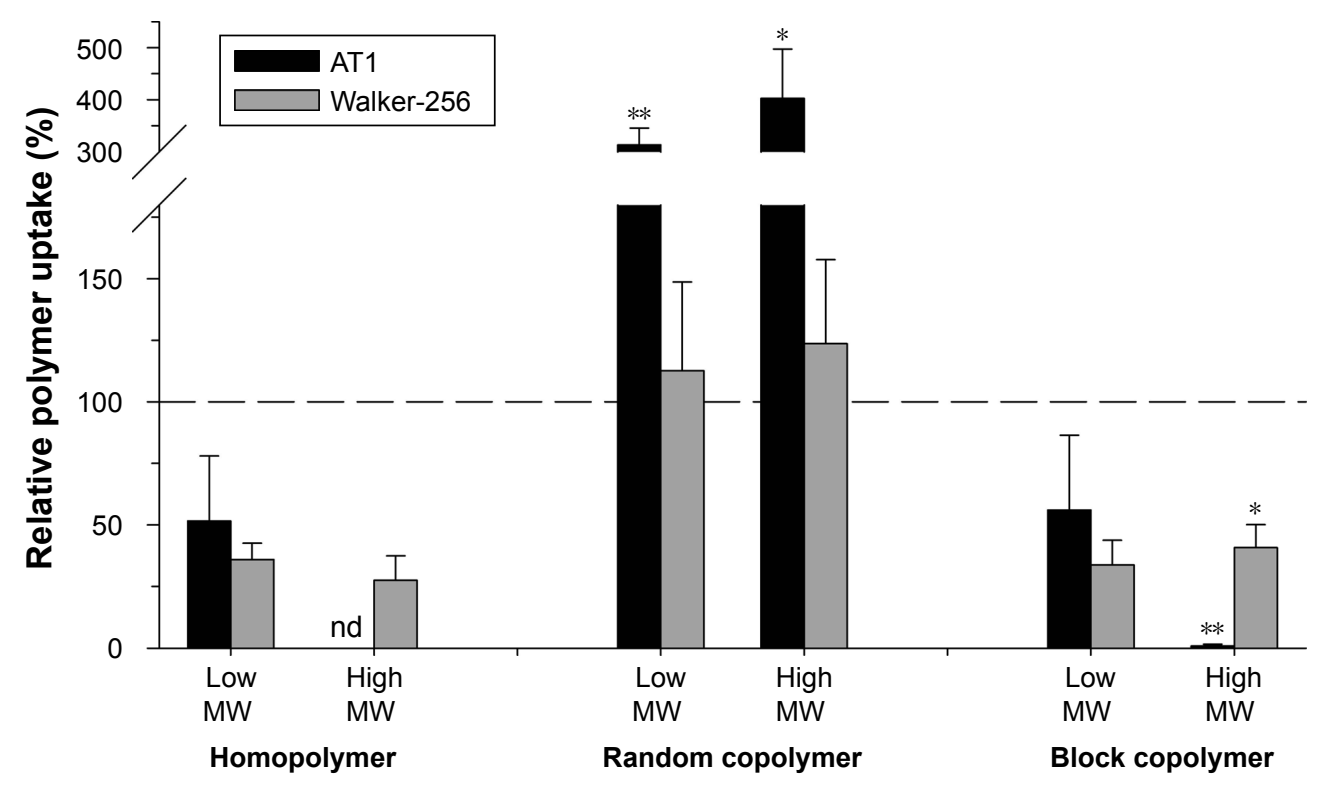

Figure 2 Impact of extracellular acidosis ( $\mathrm{pH}$ 6.6) on the cellular uptake of the polymers (homopolymer and random and block copolymers with low and high MW, respectively) in ATI and Walker-256 cells.

Notes: Values are normalized to control conditions ( $\mathrm{pH} 7.4)$. $\mathrm{n}=6-12, * \mathrm{p}<0.05, * * \mathrm{p}<0.0 \mathrm{I}$.

Abbreviations: $\mathrm{MW}$, molecular weight; nd, not detectable. 


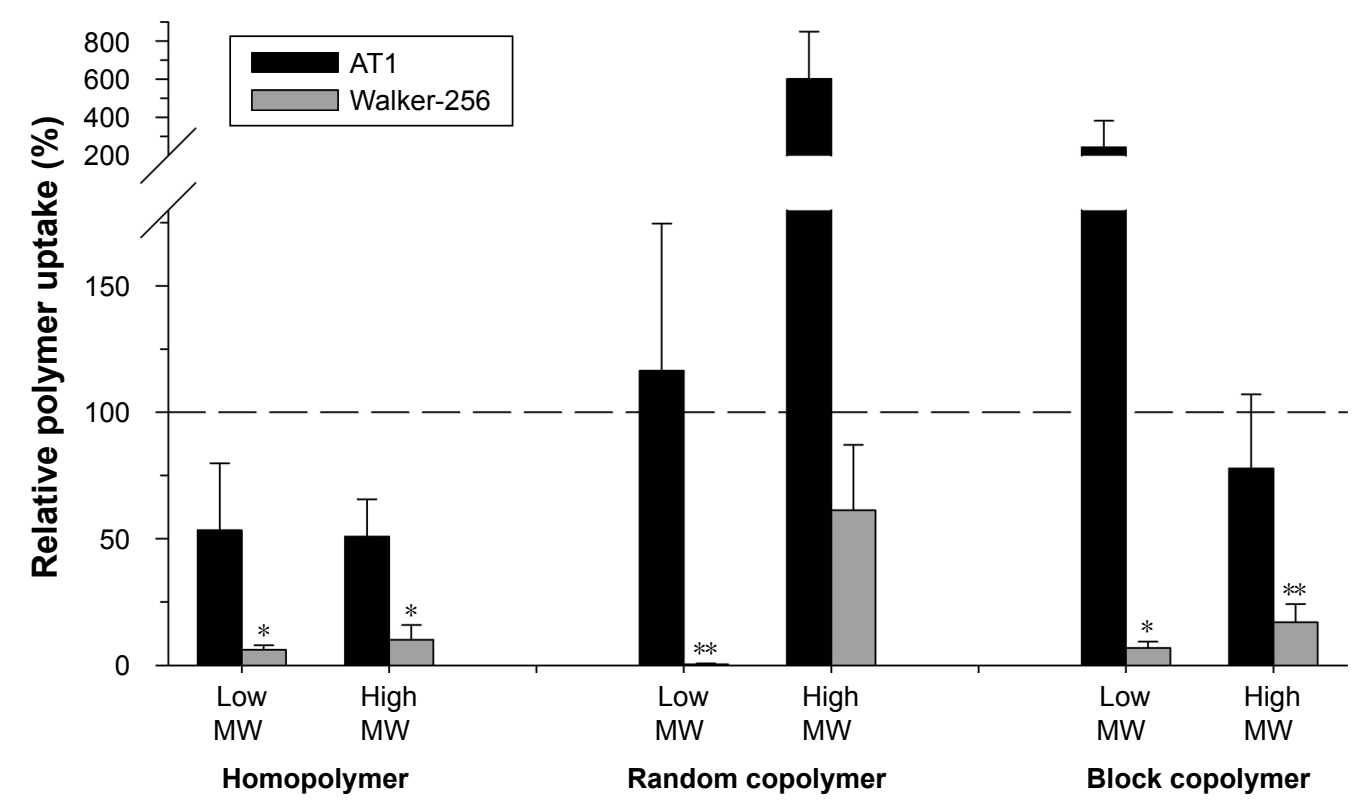

Figure $3 \mathrm{Impact}$ of hypoxia $\left(\mathrm{pO}_{2} \approx 1.5 \mathrm{mmHg}\right)$ on the cellular uptake of the polymers (homopolymer and random and block copolymers with low and high $\mathrm{MW}$, respectively) in ATI and Walker-256 cells.

Notes: Values are normalized to control conditions $\left(\mathrm{pO}_{2} \approx 150 \mathrm{mmHg}\right) . \mathrm{n}=6-8, * p<0.05, * * p<0.01$

Abbreviation: MW, molecular weight.

measurements varied considerably leading to nonsignificant results. However, acute hypoxia had a strong effect in Walker-256 cells in which the uptake was significantly reduced by $80 \%-90 \%$.

These results clearly indicate that the cellular uptake of nanoscale drug carriers is affected by the metabolic microenvironment in tumors, namely, the hypoxic and acidic milieu which both are common features of human tumors. ${ }^{18}$ However, the impact, especially of hypoxia, was cell line dependent showing a strong reduction in Walker-256 cells, whereas in AT1 cells no significant changes were seen. In many cases, the uptake was markedly reduced independently of the molecular structure of the polymer, its molecular weight or the tumor cell line investigated. Studies with gold nanoparticles showed that exposing tumor cells to hypoxia for $18 \mathrm{~h}$ increased the cellular uptake. ${ }^{31}$ This long-term hypoxia probably changes gene expression, which may impact the drug transport. In the current study, cells were exposed to hypoxia only for $2 \mathrm{~h}$ thus temporal changes in the ATP yield but no changes in gene expression can occur in this experiment.

Previous studies with the same tumor line also showed that incubation for 3-6 $\mathrm{h}$ at these adverse environmental conditions did not induce apoptotic or necrotic cell death ${ }^{32}$ so that the observed differences in polymer uptake cannot be attributed to altered cell viability. The current results indicate that the metabolic micromilieu of tumor may modulate (increase or decrease) the efficacy of HPMA-based drug carriers for chemotherapy.

\section{Impact of extracellular acidosis and hypoxia on different endocytotic routes}

Figure 4 shows the dependency of different endocytotic routes on the extracellular $\mathrm{pH}$. The macropinocytotic pathway has been analyzed by measuring the uptake of $70 \mathrm{kDa}$ dextran, which is a marker for the endocytosis from the fluid phase..$^{33}$ The absolute baseline dextran uptake at $\mathrm{pH} 7.4$ was cell line dependent. In AT1 cells, it was $3.0 \pm 0.1$ times higher than in Walker-256 cells. With decreasing $\mathrm{pH}$, the dextran uptake changed but in a cell line-dependent manner. In AT1 cells, macropinocytosis decreased from $\mathrm{pH} 7.4$ to 6.2 by $~ 70 \%$, whereas in Walker-256 cells the uptake at $\mathrm{pH} 6.2$ was 2.4 times higher as compared to control conditions at pH 7.4 (Figure 4A; values shown are normalized to the control condition at $\mathrm{pH}$ 7.4). Obviously, both cell lines reacted differently on the change of the extracellular $\mathrm{pH}$. The reason for this fundamentally different behavior is currently not fully understood.

The cellular uptake of transferrin that is used as a measure of $\mathrm{CME}^{29}$ showed a slight correlation with $\mathrm{pH}$ in both cell lines. The absolute baseline uptake at pH 7.4 in AT1 cells was $30 \% \pm 2 \%$ lower than that in Walker- 256 cells. Figure 4B shows the changes of uptake with decreasing $\mathrm{pH}$ (values shown are normalized to the control condition at $\mathrm{pH}$ 7.4). 
A

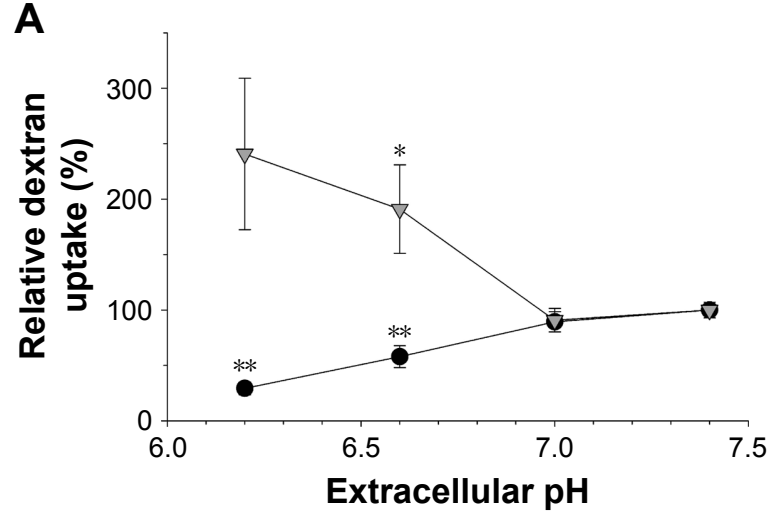

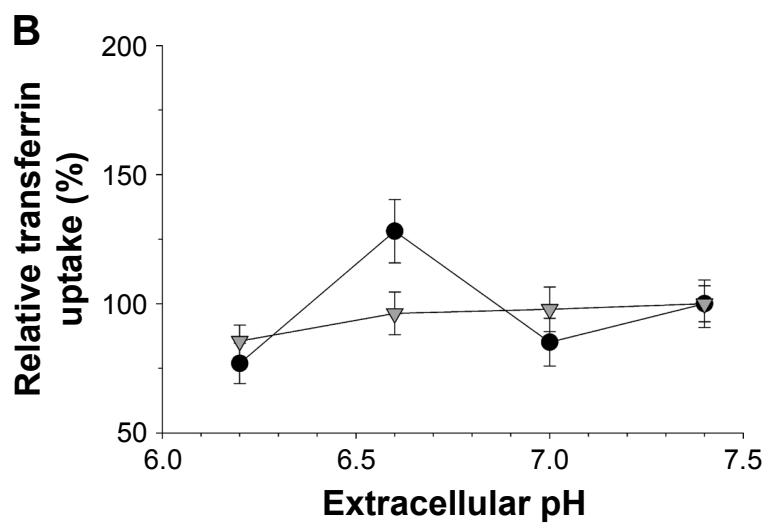

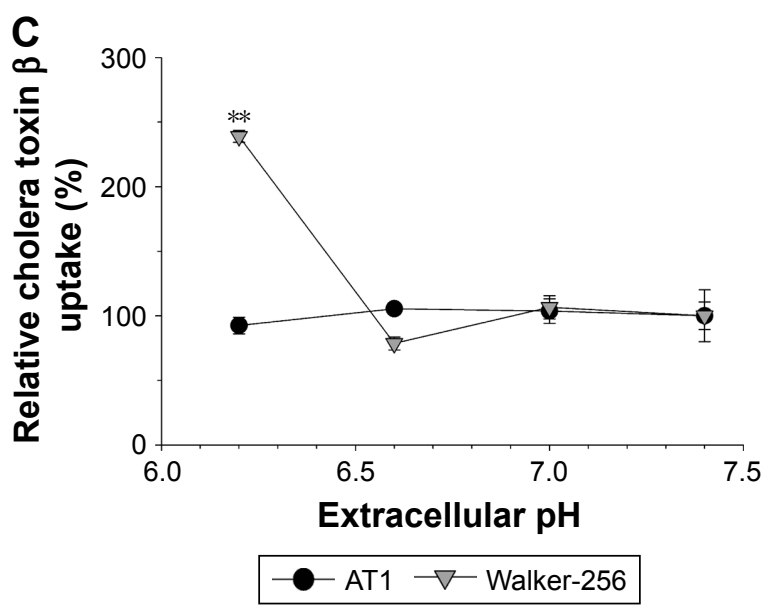

Figure 4 Impact of extracellular $\mathrm{pH}$ on the cellular uptake of $(\mathbf{A})$ dextran (macropinocytosis), (B) transferrin (CME) and (C) cholera toxin $B$ (cholesterol-dependent endocytosis) in ATI and Walker-256 cells.

Notes: Values are normalized to control conditions ( $\mathrm{pH} 7.4) . \mathrm{n}=6-13, * \mathrm{p}<0.05$, $* * p<0.01$ vs $\mathrm{pH} 7.4$

Abbreviation: CME, clathrin-mediated endocytosis.

The uptake slightly decreased; however, this change was not statistically significant.

The cholesterol-dependent endocytosis was measured by cholera toxin $\beta$ uptake. ${ }^{30}$ The absolute baseline uptake in AT1 cells (at $\mathrm{pH} 7.4$ ) was $17 \pm 2$ times stronger than that in Walker-256 cells, and it was independent of the extracellular $\mathrm{pH}$ in both cell lines (Figure 4C; values shown are normalized to the control condition at $\mathrm{pH}$ 7.4). Only at $\mathrm{pH}$ 6.2, the uptake in Walker-256 cells increased significantly as compared to $\mathrm{pH}$ 7.4. Since the low uptake rate in Walker-256 cells was close to the detection limit, the increase at $\mathrm{pH} 6.2$ could also be a random phenomenon.

In conclusion, these results indicate that at least the process of macropinocytosis is affected by the extracellular $\mathrm{pH}$ of the tissue. However, the net effect (increase or decrease) seems to be cell line specific. A pH dependency of endocytotic processes has been described almost exclusively for the entry of viruses into cells..$^{34,35}$ In this study, the phenomenon was mostly attributed to changes in the charge of the virus particles, which allows fusion with the cell membrane. ${ }^{34}$ However, since, in the current study, only uncharged dextran has been used for the analysis of macropinocytosis, this mechanism cannot explain the observed $\mathrm{pH}$ dependency. Macropinocytosis has also been described to be Cdc42 dependent. ${ }^{36}$ Since extracellular acidosis can affect Rho GTPases, ${ }^{37}$ it could be possible that macropinocytosis is regulated by the extracellular $\mathrm{pH}$ mediated by $\mathrm{Cdc} 42$. Since, for the two cell lines used, the Cdc42 status is not known, the opposed effects in the two cancer lines may be attributed to differences in the Rho GTPase status.

Figure 5 shows the impact of short-term hypoxia on dextran uptake (macropinocytosis). Once again the effect was cell line specific. In AT1 cells, which show a higher uptake under control conditions, $\mathrm{pO}_{2}$ of $1.5 \mathrm{mmHg}$ reduced macropinocytosis by $\sim 50 \%$, whereas in Walker-256 cells, this process was almost $\mathrm{O}_{2}$ independent.

Since hypoxia is also suitable to activate Rho-GTPases as part of the stress response, ${ }^{38}$ this behavior may rely on a 


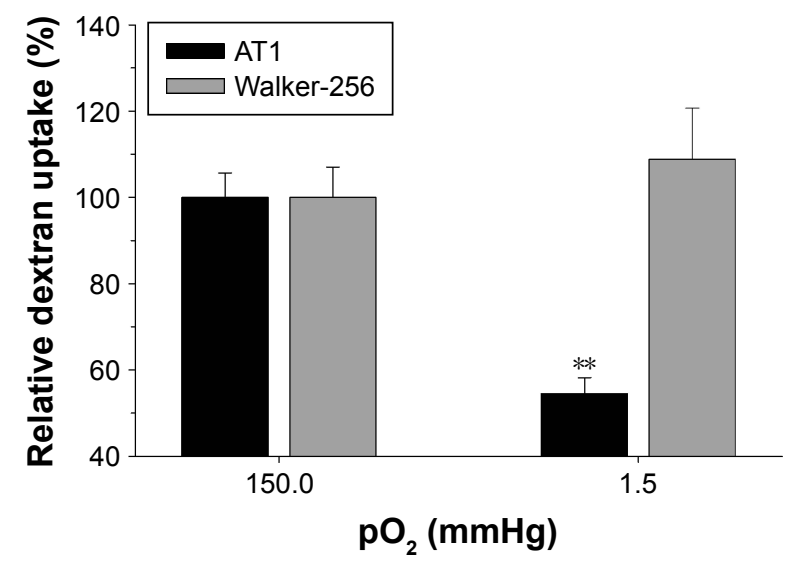

Figure $\mathbf{5}$ Impact of hypoxia on the cellular uptake of dextran (macropinocytosis) in ATI and Walker-256 cells.

Notes: Values are normalized to control conditions $\left(\mathrm{pO}_{2} \approx 150 \mathrm{mmHg}\right) . \mathrm{n}=6-13$, $* * P<0.0$ I.

similar mechanism as the acidosis-dependent changes. However, also other mechanisms have to be discussed, which may explain the cell line-specific differences. In cancer cells, p53 and RAS have been shown to modulate these endocytotic pathways. ${ }^{420,39}$ Mutant forms of p53 or altered response to activated receptor tyrosine kinases may modulate the endocytotic response to low $\mathrm{pO}_{2}{ }^{4}$

\section{Different endocytotic routes of polymer uptake}

The uptake of the different HPMA-based polymers was dependent on the extracellular $\mathrm{pH}$ and $\mathrm{pO}_{2}$ (Figures 2 and 3), whereas these effects varied between the different polymers (homopolymer, random copolymer or block copolymer). On the other hand, the various routes of endocytosis showed also a dependency on $\mathrm{pH}$ or $\mathrm{pO}_{2}$ (Figure 4). One possible explanation for the polymer results could be that the different polymers were taken up by different mechanisms of endocytosis. To test this hypothesis, the polymer uptake was measured when cells were incubated with inhibitors of different endocytotic pathways.

Rottlerin, an inhibitor of the PKC $\delta$, is known to selectively inhibit the process of macropinocytosis. ${ }^{28}$ Figure $6 \mathrm{~A}$ shows the polymer uptake during rottlerin incubation. The changes were cell line specific and polymer specific. In AT1 cells, the accumulation of both copolymers (independent of the molecular weight) was almost unaffected from the incubation with rottlerin, indicating that macropinocytosis seemed not to play a major role for these polymers in AT1 cells. The small homopolymer was not detectable after inhibition with rottlerin. Surprisingly, the high-molecular-weight homopolymer showed, in AT1 cells, a more than 20 times higher cellular uptake after PKC $\delta$ inhibition. This effect was seen in all replicates of the experiment, and it was independent of the cell line passage used. Similar results were seen with all inhibitor experiments with the large homopolymer in AT1 cells (Figures 6 and 7). Currently, the reason for the enhanced uptake of the large homopolymer in AT1 cells when incubated with any of the inhibitors remains unclear.

Nystatin is known to deplete cholesterol from lipid rafts/ caveolae that inhibits the cholesterol-mediated endocytosis. ${ }^{3}$ Figure $6 \mathrm{~B}$ shows the impact of nystatin on the polymer uptake in both cell lines. The uptake of the block copolymer was significantly reduced when inhibiting the cholesteroldependent pathway, indicating an important role of this route for the uptake of these large structures. But the uptake
A

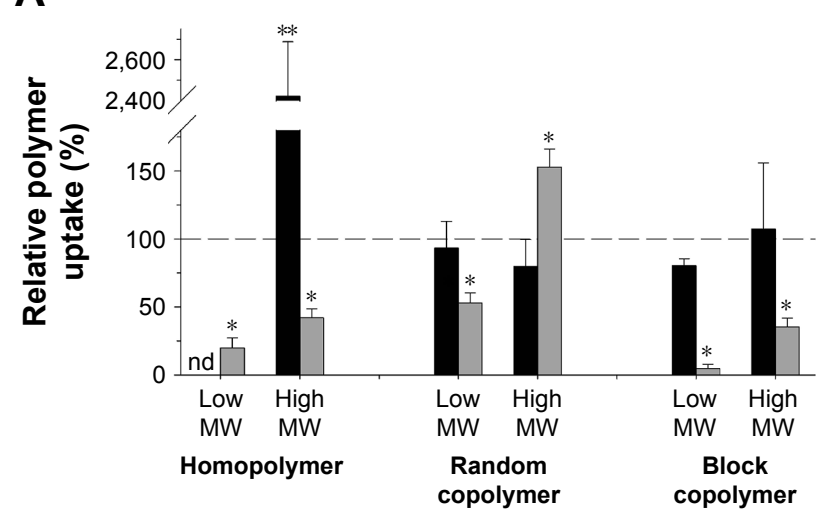

B

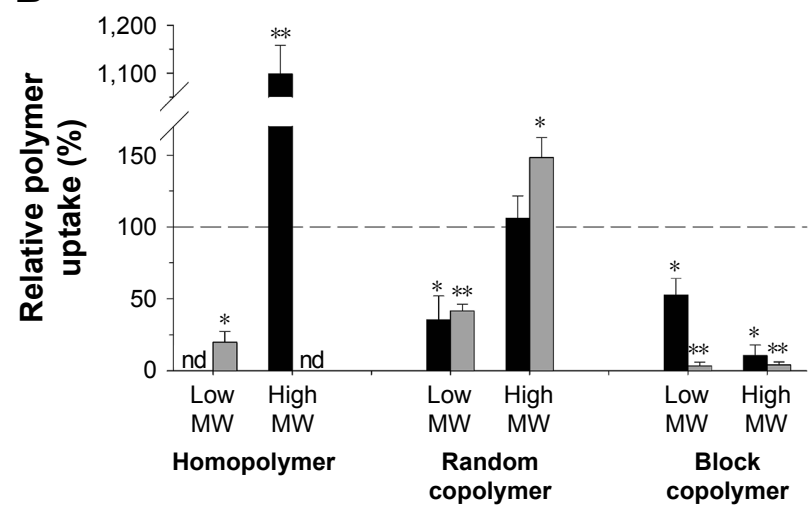

Figure 6 Impact of $(\mathbf{A})$ rottlerin (inhibitor of the PKC $\delta$ ) and (B) nystatin (inhibitor of the cholesterol-mediated endocytosis) on the cellular uptake of the polymers (homopolymer and random and block copolymers with low and high MW, respectively) in ATI and Walker-256 cells.

Notes: Values are normalized to control conditions without inhibitor. $n=6-15, * P<0.05, * * P<0.01$.

Abbreviations: MW, molecular weight; nd, not detectable. 
A

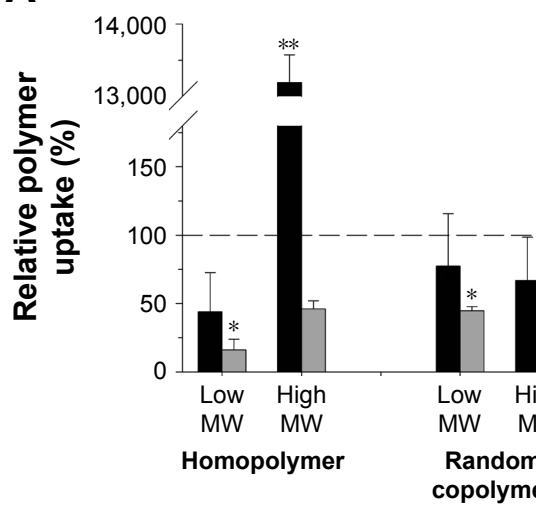

B

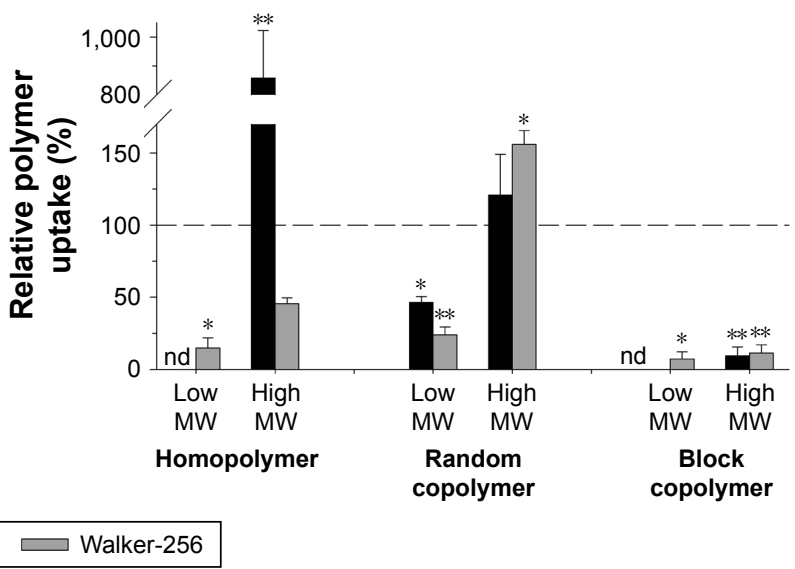

Figure 7 Impact of (A) chlorpromazine (inhibitor of the CME) and (B) dynasore (inhibitor of dynamin) on the cellular uptake of the polymers (homopolymer and random and block copolymers with low and high MW, respectively) in ATI and Walker-256 cells.

Notes: Values are normalized to control conditions without inhibitor. $\mathrm{n}=6-15, * \mathrm{p}<0.05, * * \mathrm{p}<0.01$.

Abbreviations: CME, clathrin-mediated endocytosis; MW, molecular weight; nd, not detectable.

of the small random copolymer was also hindered in both cell lines. Since the copolymers contain lipophilic LMA segments, these results indicate that the uptake of polymers with a hydrophobic structure requires (at least partially) cholesterol-rich membrane microdomains. The uptake of the HPMA homopolymers was also altered by nystatin, at which in some case an active uptake was not detectable. Once again treating the cells with nystatin led to a dramatic increase in the uptake of the large homopolymer in AT1 cells which, currently, cannot be explained sufficiently.

Another important uptake mechanism is the CME. In this process, clathrin molecules on the inner wall of the cell membrane form a network that shapes a clathrin-coated pit. Finally, dynamin together with other molecules forms the vesicle neck, which results in a scission of the vesicle in the intracellular space. ${ }^{3}$ To analyze the impact of these processes for the polymer uptake, the clathrin net formation was blocked by chlorpromazine, and the dynamin-dependent displacement of the vesicle was inhibited by dynasore. ${ }^{27}$

In both cell lines, the inhibition of clathrin as well as dynamin significantly reduced the uptake of the block copolymer more or less independently of their molecular weight (Figure 7), which indicates that CME seems to play a role for the uptake of these polymers. For the random copolymers, this endocytotic route appears to be of less importance. Inhibition of the clathrin net formation had only minor effects on the random copolymer uptake (Figure 7A). Inhibition of dynamin reduced only the uptake of random copolymer with low molecular weight by $50 \%-70 \%$ (Figure 7B). For homopolymers, the uptake was markedly reduced in Walker-256 cells but not in AT1 cells (once again showing the surprising result that the uptake of large homopolymer was much stronger in AT1 cells when clathrin or dynamin was inhibited).

Taking these results together, it becomes obvious that the route of the cellular uptake of the different polymers varies between the chemical structures of the molecules and (to a minor extent) between the cell lines evaluated.

The uptake of the homopolymer with low molecular weight (which was 10 times higher in Walker-256 than in AT1 cells) could be markedly reduced in both cell lines by inhibiting all routes analyzed, indicating that this type of polymer is taken up by macropinocytosis as well as by CME and clathrin-independent endocytosis. In Walker-256 cells, the large homopolymer showed an uptake pattern comparable to that of the small counterpart (Figures 6 and 7; gray bars). Obviously, the homopolymer is taken up by different endocytotic pathways (macropinocytosis and clathrin-dependent and clathrin-independent endocytosis). A similar pattern with the uptake to be significantly reduced by all inhibitors was seen for the p(HPMA)- $b$-p(LMA) block copolymer (independently of the molecular size and the cell line used). The block copolymers also seemed to be taken up by different endocytotic routes. This comparable uptake pattern may be the result of similar physicochemical characteristics of both polymer structures. Homopolymers and block copolymers showed a strong hydrophilic surface since in the block copolymers the lipophilic LMA segments were located in the core of the resulting superstructure. ${ }^{11,12}$ For the uptake from the fluid phase, various routes (macropinocytosis, clathrin-dependent endocytosis or clathrin-independent endocytosis) are responsible. ${ }^{3}$ For this reason, the results 
shown in Figures 6 and 7 are according to the hydrophilic properties of these polymers. The molecular size (molecular weight, hydrodynamic radius of the superstructure) had almost no impact on the uptake route.

Results comparable to those of the $\mathrm{p}$ (HPMA)- $b$-p(LMA) block copolymers in the current study have been described for other amphiphilic triblock copolymers (containing poly(ethylene oxide), poly(propylene oxide) and Pluronic P85) in which the hydrophobic segments are located in the center of the structure and the hydrophilic segments form a corona on the surface. ${ }^{40}$ Sahay et $\mathrm{al}^{41}$ showed that these structures are also taken up by several endocytotic pathways such as caveolae-mediated endocytosis but also by caveolae- and clathrin-independent mechanisms. Obviously, large block copolymer structures with a hydrophilic surface and a lipophilic core are taken up by a broad spectrum of endocytotic mechanisms. The size of the p(HPMA)- $b$-p(LMA) block copolymers, however, seems to be of less importance, which has been already described for other nanocarriers. ${ }^{42}$

For p(HPMA) homopolymers, it has been described that the uptake is also mediated by different endocytotic routes (caveolae-mediated endocytosis, non-clathrin and noncaveolae-dependent endocytosis, macropinocytosis). However, the degree of the impact of the respective endocytotic route on the uptake varied markedly between different cell lines tested. ${ }^{43}$ These results are comparable to those found in the current study. It seems that the hydrophilic surface of the polymer is predominately important for the uptake by numerous endocytotic pathways. ${ }^{42}$ A predominant factor for selecting different endocytotic routes seems to be the surface charge. Liu et $\mathrm{al}^{25}$ analyzed the uptake of $\mathrm{p}$ (HPMA) polymer containing various positively or negatively charged groups as well as hydrophobic side chains. They demonstrated that positively charged copolymers were taken up by CME, micropinocytosis as well as dynamin-dependent endocytosis. Polymers with a weak negative charge were also taken up by all three mechanisms but to a much lesser extent, whereas strongly negative polymers are taken up predominately by macropinocytosis.

In the random $\mathrm{p}(\mathrm{HPMA})-\mathrm{co}$-p(LMA) copolymers, the lipophilic LMA segments are located in the core but also on the surface of the structure ${ }^{11,15}$ resulting in a more lipophilic molecule. Hydrophobic molecules have been proposed to be taken up by mechanisms associated with cholesterolrich membrane rafts by caveolae- and clathrin-independent pathways. ${ }^{42,44}$ In the current study, the cellular uptake of random $\mathrm{p}$ (HPMA)-co-p(LMA) copolymers differed from the other types. The lipophilic polymer properties reduced the uptake if the membrane was cholesterol depleted (by nystatin), which seemed to reduce the adherence of the lipophilic polymer to the cell membrane. ${ }^{3}$ The uptake of the random copolymer was also hindered by the inhibition of dynamin (by dynasore) but not by the inhibition of CME. This can be explained by the fact that endocytosis of lipid rafts depends on dynamin but not on clathrin. ${ }^{45}$ The random copolymer seemed to be taken up preferentially by cholesterol-dependent lipid raft endocytosis. However, this effect was only seen in the polymers with low molecular weight, whereas the large molecules showed only weak, nonuniform dependency (Figures 6 and 7). In the random copolymers with low and high molecular weight, the HPMA-LMA ratio was different between small and large polymers. The lowmolecular-weight polymer contained 18\% lipophilic LMA segments, whereas large polymers contained 25\% (Table 1). The current results could be explained if a higher LMA ratio would lead to a more pronounced orientation of the lipophilic segments in the polymer core ${ }^{11}$ leading to a more hydrophilic surface. In this case, the dependency of uptake from the membrane cholesterol content would be reduced. However, this hypothesis has to be validated in further experiments.

Another aspect of polymers with hydrophobic segments on the surface has to be taken into account. Strong binding of these polymers to lipid rafts of the membrane may affect the further release of these compounds to subcellular compartments. It has been proposed that macromolecules that bind to lipid rafts allow for cellular internalization and vesicular trafficking to non-lysosomal subcellular compartments. ${ }^{46}$ This could be attractive to nondegradative intracellular drug delivery but may limit the drug transport of compounds covalently bound to nanocarriers. In these, mostly the drug has to be released in a hydrophilic environment of the lysosomal compartment to become cytotoxic. Currently, it remains unclear into which cellular compartment the different polymers are transported. This can be analyzed in future studies by fluorescence microscopy studies. It has to be also investigated whether the high cellular uptake of the random $\mathrm{p}$ (HPMA)-co-p(LMA) copolymer (Figure 1) is associated with a better drug delivery of covalently bound drugs in AT1 cells or whether the nanocarrier stays in the lipophilic environment of the cell membrane.

An important aspect of the current study is the cell line specificity of the results obtained showing pronounced differences in the baseline uptake of the different polymers but also in some of the endocytotic routes. Such differences have also been described previously by others. ${ }^{43}$ It has to be analyzed whether the intrinsic activity of the various endocytotic 
mechanisms is different in the cell lines or whether the interaction of the polymer with the cell membrane varies. In this study, a detailed analysis of the membrane composition (eg, lipid raft content or cholesterol content) could be indicative.

\section{Conclusion}

The current results reveal that the cellular uptake of polymeric nanoparticles depends on their molecular structure, the molecular weight and the individual tumor. In AT1 prostate cancer cells that take up polymers quite poorly per se, the partly lipophilic random $\mathrm{p}$ (HPMA)-co-p(LMA) copolymer has been shown to enter the cells better by a factor of 5 . However, the results also show that the cellular uptake does not correlate with overall accumulation measurements in the tumor tissue in vivo. ${ }^{14,15}$ Therefore, the drug transport to the tissue depends on parameters of microcirculation and vascular permeability as well as on active endocytosis; however, these parameters are independent of each other.

The study also clearly shows that the cellular uptake depends on microenvironmental parameters of the tumor tissue such as acidosis or hypoxia. However, this impact of metabolic parameters was also dependent on the polymer structure and the individual cell line. Acidosis can not only foster the uptake (random copolymer in AT1 cells) but also significantly reduce endocytosis (block copolymer in Walker256 cells). These results indicate that it is difficult to predict the potential beneficial effect of nanocarrier drug transport since $\mathrm{pH}$ or $\mathrm{pO}_{2}$ can vary within the tumor tissue profoundly in space and time. ${ }^{17,47}$

Finally, the analysis of the endocytotic route by which the polymers were taken up into the cell showed a dependency on the molecular structure of the molecule. The hydrophilic HPMA homopolymer and p(HPMA)- $b$-p(LMA) block copolymer are taken up by all mechanisms evaluated (macropinocytosis, CME, dynamin-dependent processes and cholesterol-dependent endocytosis). The more lipophilic random $\mathrm{p}$ (HPMA)-co-p(LMA) copolymer seems to be taken up preferentially by the cholesterol- and dynamindependent (clathrin-independent) endocytotic way. The differences between random copolymers of different sizes indicate that the degree of lipophilicity on the outer surface of the superstructure seems to be a determining factor for this uptake route.

The study indicates some problems of using HPMAbased polymeric nanoparticles as drug carriers in clinical oncology. The uptake is affected by properties of the polymer molecule (structure, size, lipophilicity) but also by parameters of the individual tumor (perfusion, vascular permeability, microenvironmental parameters and activity of different endocytotic routes). These parameters can positively or negatively modulate the transport of drugs to the tumor tissue and into the cells. Thus, the net effect of drug transport by nanocarriers in the clinical situation is difficult to predict.

\section{Acknowledgment}

The authors are very thankful for the financial support of the Deutsche Forschungsgemeinschaft (DFG) (Oliver Thews: TH 482/4-1; Rudolf Zentel: ZE 230/21-1).

\section{Disclosure}

The authors report no conflicts of interest in this work.

\section{References}

1. Maeda H, Nakamura H, Fang J. The EPR effect for macromolecular drug delivery to solid tumors: improvement of tumor uptake, lowering of systemic toxicity, and distinct tumor imaging in vivo. Adv Drug Deliv Rev. 2013;65(1):71-79.

2. Hillaireau H, Couvreur P. Nanocarriers' entry into the cell: relevance to drug delivery. Cell Mol Life Sci. 2009;66(17):2873-2896.

3. Doherty GJ, McMahon HT. Mechanisms of endocytosis. Аnпи Rev Biochem. 2009;78:857-902.

4. Mellman I, Yarden Y. Endocytosis and cancer. Cold Spring Harb Perspect Biol. 2013;5(12):a016949.

5. Anderson RG. The caveolae membrane system. Annu Rev Biochem. 1998;67:199-225.

6. Rodal SK, Skretting G, Garred O, Vilhardt F, van Deurs B, Sandvig K Extraction of cholesterol with methyl-beta-cyclodextrin perturbs formation of clathrin-coated endocytic vesicles. Mol Biol Cell. 1999;10(4): 961-974.

7. Duncan R. Development of HPMA copolymer-anticancer conjugates: clinical experience and lessons learnt. Adv Drug Deliv Rev. 2009;61(13) 1131-1148.

8. Kopeček J, Kopečkova P. HPMA copolymers: origins, early developments, present, and future. Adv Drug Deliv Rev. 2010;62(2): $122-149$

9. Ulbrich K, Subr V. Structural and chemical aspects of HPMA copolymers as drug carriers. Adv Drug Deliv Rev. 2010;62(2):150-166.

10. Hemmelmann M, Knoth C, Schmitt U, et al. HPMA based amphiphilic copolymers mediate central nervous effects of domperidone. Macromol Rapid Commun. 2011;32(9-10):712-717.

11. Hemmelmann M, Metz VV, Koynov K, Blank K, Postina R, Zentel R. Amphiphilic HPMA-LMA copolymers increase the transport of Rhodamine 123 across a BBB model without harming its barrier integrity. J Control Release. 2012;163(2):170-177.

12. Barz M, Luxenhofer R, Zentel R, Kabanov AV. The uptake of N-(2hydroxypropyl)-methacrylamide based homo, random and block copolymers by human multi-drug resistant breast adenocarcinoma cells. Biomaterials. 2009;30(29):5682-5690.

13. Nuhn L, Barz M, Zentel R. New perspectives of HPMA-based copolymers derived by post-polymerization modification. Macromol Biosci. 2014;14(5):607-618.

14. Allmeroth M, Moderegger D, Biesalski B, et al. Modifying the body distribution of HPMA-based copolymers by molecular weight and aggregate formation. Biomacromolecules. 2011;12(7):2841-2849.

15. Allmeroth $\mathrm{M}$, Moderegger $\mathrm{D}$, Gündel $\mathrm{D}$, et al. HPMA-LMA copolymer drug carriers in oncology: an in vivo PET study to assess the tumor line-specific polymer uptake and body distribution. Biomacromolecules. 2013;14(9):3091-3101. 
16. Allmeroth M, Moderegger D, Gündel D, et al. PEGylation of HPMA-based block copolymers enhances tumor accumulation in vivo: a quantitative study using radiolabeling and positron emission tomography. J Control Release. 2013;172(1):77-85.

17. Thews O, Vaupel P. Spatial oxygenation profiles in tumors during normo- and hyperbaric hyperoxia. Strahlenther Onkol. 2015;191(11): $875-882$.

18. Vaupel P, Kallinowski F, Okunieff P. Blood flow, oxygen and nutrient supply, and metabolic microenvironment of human tumors: a review. Cancer Res. 1989;49(23):6449-6465.

19. Bourseau-Guilmain E, Menard JA, Lindqvist E, et al. Hypoxia regulates global membrane protein endocytosis through caveolin-1 in cancer cells. Nat Commun. 2016;7:11371.

20. Wang Y, Ohh M. Oxygen-mediated endocytosis in cancer. J Cell Mol Med. 2010;14(3):496-503.

21. Wang Y, Roche O, Yan MS, et al. Regulation of endocytosis via the oxygen-sensing pathway. Nat Med. 2009;15(3):319-324.

22. Kong X, Tang X, Du W, et al. Extracellular acidosis modulates the endocytosis and maturation of macrophages. Cell Immunol. 2013; 281(1):44-50.

23. Park SY, Bae DJ, Kim MJ, Piao ML, Kim IS. Extracellular low $\mathrm{pH}$ modulates phosphatidylserine-dependent phagocytosis in macrophages by increasing stabilin-1 expression. J Biol Chem. 2012;287(14): 11261-11271.

24. Riemann A, Wußling H, Loppnow H, Fu H, Reime S, Thews O. Acidosis differently modulates the inflammatory program in monocytes and macrophages. Biochim Biophys Acta. 2016;1862(1):72-81.

25. Liu J, Bauer H, Callahan J, Kopečkova P, Pan H, Kopeček J. Endocytic uptake of a large array of HPMA copolymers: elucidation into the dependence on the physicochemical characteristics. J Control Release. 2010;143(1):71-79.

26. Gekle M, Mildenberger S, Freudinger R, Silbernagl S. Endosomal alkalinization reduces $\mathrm{J}_{\max }$ and $\mathrm{K}_{\mathrm{m}}$ of albumin receptor-mediated endocytosis in OK cells. Am J Physiol. 1995;268(5 pt 2):F899-F906.

27. Mulcahy LA, Pink RC, Carter DR. Routes and mechanisms of extracellular vesicle uptake. J Extracell Vesicles. 2014;3:24641.

28. Sarkar K, Kruhlak MJ, Erlandsen SL, Shaw S. Selective inhibition by rottlerin of macropinocytosis in monocyte-derived dendritic cells. Immunology. 2005;116(4):513-524.

29. Mayor S, Pagano RE. Pathways of clathrin-independent endocytosis. Nat Rev Mol Cell Biol. 2007;8(8):603-612.

30. Torgersen ML, Skretting G, van Deurs B, Sandvig K. Internalization of cholera toxin by different endocytic mechanisms. J Cell Sci. 2001; 114(pt 20):3737-3747.

31. Neshatian M, Chung S, Yohan D, Yang C, Chithrani DB. Uptake of gold nanoparticles in breathless (hypoxic) cancer cells. J Biomed Nanotechnol. 2015;11(7):1162-1172.
32. Riemann A, Schneider B, Ihling A, et al. Acidic environment leads to ROS-induced MAPK signaling in cancer cells. PLoS One. 2011; 6(7): 22445 .

33. Shurety W, Stewart NL, Stow JL. Fluid-phase markers in the basolateral endocytic pathway accumulate in response to the actin assemblypromoting drug Jasplakinolide. Mol Biol Cell. 1998;9(4):957-975.

34. Bitto D, Halldorsson S, Caputo A, Huiskonen JT. Low $\mathrm{pH}$ and anionic lipid-dependent fusion of Uukuniemi phlebovirus to liposomes. $J$ Biol Chem. 2016;291(12):6412-6422.

35. Mercer J, Knebel S, Schmidt FI, Crouse J, Burkard C, Helenius A. Vaccinia virus strains use distinct forms of macropinocytosis for hostcell entry. Proc Natl Acad Sci U S A. 2010;107(20):9346-9351.

36. Garrett WS, Chen LM, Kroschewski R, et al. Developmental control of endocytosis in dendritic cells by Cdc42. Cell. 2000;102(3):325-334.

37. Hyvelin JM, O'Connor C, McLoughlin P. Effect of changes in $\mathrm{pH}$ on wall tension in isolated rat pulmonary artery: role of the RhoA/Rhokinase pathway. Am J Physiol Lung Cell Mol Physiol. 2004;287(4): L673-L684.

38. Krook MA, Nicholls LA, Scannell CA, Chugh R, Thomas DG, Lawlor ER. Stress-induced CXCR4 promotes migration and invasion of ewing sarcoma. Mol Cancer Res. 2014;12(6):953-964.

39. Michalopoulou E, Bulusu V, Kamphorst JJ. Metabolic scavenging by cancer cells: when the going gets tough, the tough keep eating. $\mathrm{Br} J$ Cancer. 2016;115(6):635-640.

40. Batrakova EV, Kabanov AV. Pluronic block copolymers: evolution of drug delivery concept from inert nanocarriers to biological response modifiers. J Control Release. 2008;130(2):98-106.

41. Sahay G, Batrakova EV, Kabanov AV. Different internalization pathways of polymeric micelles and unimers and their effects on vesicular transport. Bioconjug Chem. 2008;19(10):2023-2029.

42. Sahay G, Alakhova DY, Kabanov AV. Endocytosis of nanomedicines. $J$ Control Release. 2010;145(3):182-195.

43. Mohammadpour R, Safarian S, Buckway B, Ghandehari H. Comparative endocytosis mechanisms and anticancer effect of HPMA copolymerand PAMAM dendrimer-MTCP conjugates for photodynamic therapy. Macromol Biosci. 2017;17(4):1600333.

44. Kirkham M, Parton RG. Clathrin-independent endocytosis: new insights into caveolae and non-caveolar lipid raft carriers. Biochim Biophys Acta . 2005;1746(3):350-363.

45. Lajoie P, Nabi IR. Lipid rafts, caveolae, and their endocytosis. Int Rev Cell Mol Biol. 2010;282:135-163.

46. Bareford LM, Swaan PW. Endocytic mechanisms for targeted drug delivery. Adv Drug Deliv Rev. 2007;59(8):748-758.

47. Bussink J, Kaanders JH, Rijken PF, Martindale CA, van der Kogel AJ. Multiparameter analysis of vasculature, perfusion and proliferation in human tumour xenografts. Br J Cancer. 1998;77(1):57-64. 


\section{Supplementary materials}
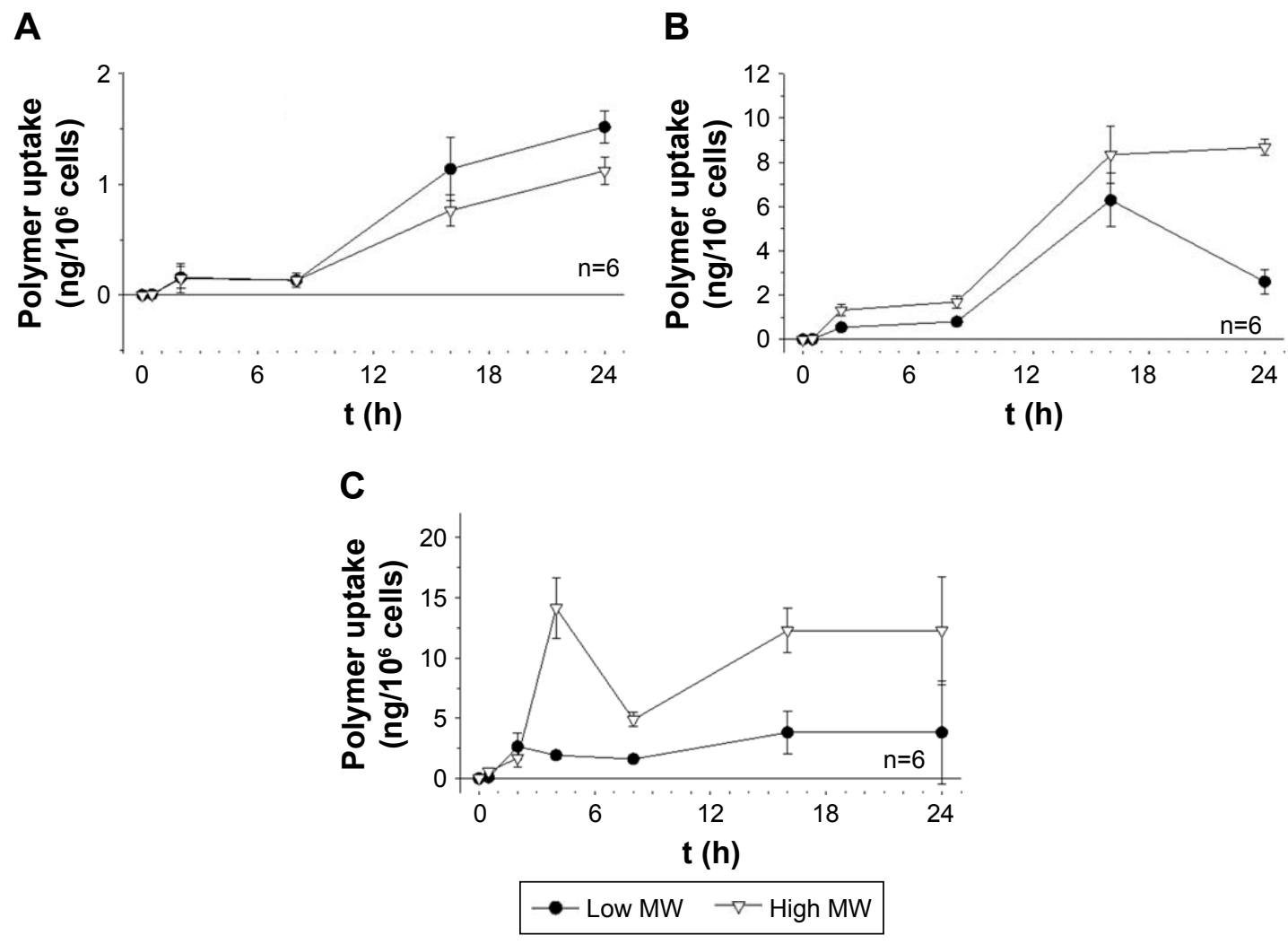

Figure SI Time course of the cellular uptake of HPMA-based (A) homopolymers, (B) random copolymer and (C) block copolymer (with low and high MW, respectively) in ATI prostate carcinoma cells.

Abbreviations: HPMA, N-(2-hydroxypropyl)methacrylamide; MW, molecular weight. 
A

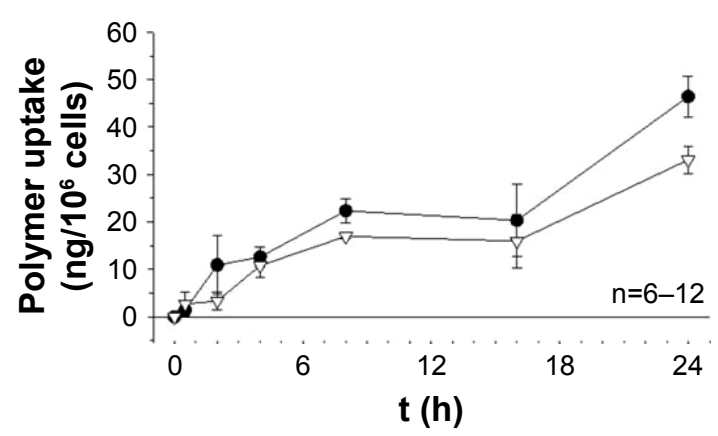

B

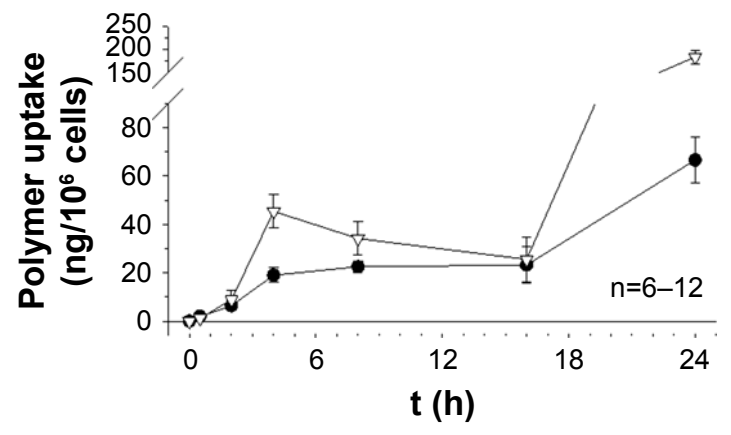

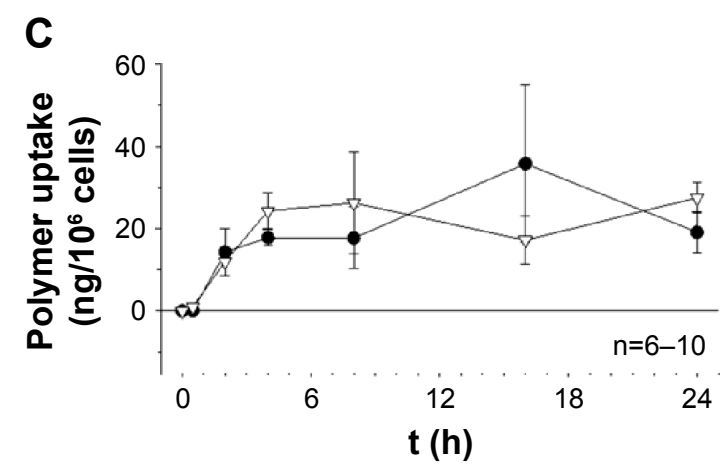

$\rightarrow$ Low MW $\rightarrow-$ High MW

Figure S2 Time course of the cellular uptake of HPMA-based (A) homopolymers, (B) random copolymer and (C) block copolymer (with low and high MW, respectively) in Walker-256 mammary carcinoma cells.

Note: $n=6-12$.

Abbreviations: HPMA, N-(2-hydroxypropyl)methacrylamide; MW, molecular weight.

\section{Publish your work in this journal}

The International Journal of Nanomedicine is an international, peerreviewed journal focusing on the application of nanotechnology in diagnostics, therapeutics, and drug delivery systems throughout the biomedical field. This journal is indexed on PubMed Central, MedLine, CAS, SciSearch ${ }^{\circledR}$, Current Contents ${ }^{\circledR} /$ Clinical Medicine,
Journal Citation Reports/Science Edition, EMBase, Scopus and the Elsevier Bibliographic databases. The manuscript management system is completely online and includes a very quick and fair peer-review system, which is all easy to use. Visit http://www.dovepress.com/ testimonials.php to read real quotes from published authors. 